TISSUE VIABILITY

\title{
Adherence to pressure ulcer prevention guidelines in home care: a survey of current practice
}

\author{
Louis Paquay MSc, RN \\ Nursing Coordinator, Wit-Gele Kruis van Vlaanderen, Brussels \& Department of General Practice, KULeuven, Belgium \\ Renild Wouters BSc \\ Researcher, Wit-Gele Kruis van Vlaanderen, Brussels, Belgium
}

Tom Defloor MSc, PhD, RN

Assistant Professor, Nursing Science, Faculty of Medicine and Health Sciences, Ghent University, Ghent, Belgium

Frank Buntinx PhD

Professor, Department of General Practice, KULeuven, Belgium \& Department of General Practice, Universiteit Maastricht, Maastricht, The Netherlands

Roseline Debaillie MSc, RN

Nursing coordinator, Wit-Gele Kruis van Vlaanderen, Brussels, Belgium

Ludo Geys MSc, RN

General coordinator, Wit-Gele Kruis van Vlaanderen, Brussels, Belgium

Submitted for publication: 22 June 2006

Accepted for publication: 16 May 2007

Correspondence:

Louis Paquay

Wit-Gele Kruis van Vlaanderen

Adolphe Lacomblélaan 69-71 bus 3

B-1030 Brussel

Belgium

Telephone: +3227393511

E-mail: louis.paquay@vlaanderen.wgk.be
PAQUAY L, WOUTERS R, DEFLOOR T, BUNTINX F, DEBAILLIE R \& GEYS L (2008) Journal of Clinical Nursing 17, 627-636

Adherence to pressure ulcer prevention guidelines in home care: a survey of current practice

Aims and objectives. To investigate the pressure ulcer prevalence in home nursing patients and to evaluate guideline adherence of measures for the prevention of pressure ulcers and the participation of informal carers in pressure ulcer prevention. Background. Since 2002, the Belgian Guideline for the Prevention of Pressure Ulcers was published on the Internet, but no information was available on guideline adherence in home care.

Methods. A cross-sectional survey of pressure ulcer prevalence and guideline adherence was performed in a cluster randomized sample of 2779 clients of nine regional nursing departments in Flanders, Belgium. The Belgian Guideline for the Prevention of Pressure Ulcers was the reference standard for the evaluation of the guideline adherence.

Results. There were 744 subjects at risk for developing pressure ulcers. The overall prevalence of pressure ulcers for the total sample population was $6 \cdot 8 \%$. The age-, sex- and risk-standardized prevalence per regional department varied between $4.9 \%$ 
and $9 \cdot 1 \%$. Of the 744 subjects at risk, $33(4 \cdot 4 \%)$ received preventive measures, which were in adherence to the Belgian Guideline for Prevention of Pressure Ulcers, 482 persons $(64.8 \%)$ were administered measures, which did not adhere to the Belgian Guideline for Prevention of Pressure Ulcers and in 229 subjects (30.8\%) at risk for developing pressure ulcers, prevention was lacking. For subjects with at least one pressure ulcer, the proportions were: $4 \cdot 8 \%$ adherence, $76 \cdot 6 \%$ no adherence and $18.6 \%$ no prevention. A proportion of $22.2 \%$ of the patients at risk and their informal carers were informed and motivated by the home care nurse to participate in the pressure ulcer prevention and their actual participation in the prevention was $21.4 \%$ of all risk cases.

Conclusions. The adherence of nurses and clients to the guideline for pressure ulcer prevention was low.

Relevance to the clinical practice. The study demonstrates a detailed evaluation of guideline adherence to pressure ulcer prevention in an individual patient situation, with special attention for materials and measures, which are not adequate and not recommended by the Belgian Guideline for the Prevention of Pressure Ulcers.

Key words: guidelines, nurses, nursing, pressure ulcer, primary care, quality of care

\section{Introduction}

Pressure ulcers are an important problem in home care. The prevalence of pressure ulcers in home care has been reported to vary between 6.0-21.3\% (Bergquist \& Frantz 1999, Meehan et al. 1999, Ferrell et al. 2000, Halfens et al. 2001, Halfens \& Bours 2002). These findings underline the importance of integrating high quality pressure ulcer prevention measures in the care processes of home care agencies. Specific practice recommendations were formulated in the guidelines for pressure ulcer prevention which became increasingly available in recent decades (Panel for the prediction and Prevention of Pressure Ulcers in Adults (AHCPR) 1992, Shekelle et al. 2001, Kwaliteitsinstituut voor de Gezondheidszorg CBO 2002).

Despite the available guidelines, surveys of home healthcare agencies suggest many shortcomings in pressure ulcer prediction and/or prevention policies. In the US Medicarecertified home care agencies, only $21 \%$ of the agencies used a validated scale for risk assessment (Bergquist 2005). In $72 \%$ of the agencies the personnel used clinical nursing judgement for pressure ulcer risk detection. Only $28 \cdot 1 \%$ of the agencies had protocols for preventive interventions. In the Netherlands, a pressure ulcer protocol was available in $78 \%$ of the home care agencies (Chaves et al. 2006). The available protocols were frequently of low quality or not updated according to the latest set of guidelines. Frequently, the healthcare workers did not receive a formal introduction to the protocol.
Process oriented studies about quality of care for nursing home residents revealed that measures for pressure ulcer prevention were rarely concordant with evidence-based guidelines and that there were numerous opportunities to improve care related to pressure ulcer prevention (Baier et al. 2003, Bates-Jensen et al. 2003, Saliba et al. 2003, Wipke-Tevis et al. 2004). In home health care, similar suboptimal pressure ulcer prevention practices were reported. In US homecare agencies, only $27 \cdot 3 \%$ of the subjects with pressure ulcers and only $14.2 \%$ of the subjects at risk for pressure ulcers had a foam mattress, alternating air mattress, or other pressure-reducing device (Ferrell et al. 2000). The authors suggested that patients at risk for developing pressure ulcers were inappropriately treated or under-treated with respect to pressure ulcer reduction.

In home health care, participation of informal carers in pressure ulcer prevention is required for the continuity of prevention. It is a major responsibility for nursing to make sure that lay bedside carers have the knowledge and ability to carry out the prevention protocol (Maklebust 1999). Patients and carers should be taught daily skin inspections and methods to reduce the intensity of pressure and shear. Patient/carer education should start immediately on admission to the home health agency (Bergquist \& Frantz 1999). Several studies reported problems with regard to the knowledge of informal carers and the instructions they received about pressure ulcer prevention. In a preliminary survey of consumer views about pressure ulcer development 
in an emergency department of one acute hospital trust, relatively few respondents $(27 \%)$ were aware that pressure ulcers could be avoided and few were aware that lying on a hospital trolley $(10 \%)$ could increase the risk (Gould et al. 2000). Although most home health agencies taught patients and carers strategies for the prevention of pressure ulcers, only $54.3 \%$ of the agencies developed teaching materials for distribution to patients at risk (Bergquist 2005). Ferrell et al. (2000) concluded that adequate patient and carer education about pressure ulcer prevention was often lacking and family and informal carers may not have the capacity to provide optimal care.

The Belgian Guideline for Prevention of Pressure Ulcers (BGPPU) was developed by order of the federal health authorities (Defloor et al. 2002). Since January 2002 the BGPPU were published on the Internet to make the evidence available to all professional health workers. In the BGPPU a clear distinction was made between recommendable and nonrecommendable materials and measures for the prevention of pressure ulcers. Recommendation for the use of each measure and material was based on the evidence-based effectiveness of the measure or material. Since 2002, no known process-ofcare oriented study used the BGPPU as the reference for investigating guideline adherence in Belgian home health care.

The purpose of the present study was to investigate three aspects of pressure ulcer care in home care patients:

1 What is the prevalence of pressure ulcers and how many patients are at risk for developing pressure ulcers in the population of home nursing patients?

2 To what extent are the measures and materials, applied for the prevention of pressure ulcers, adherent to the BGPPU?

3 What is the role of informal carers in the prevention of pressure ulcers?

\section{Methods}

\section{Design and setting}

The present study was designed as a cross-sectional survey of pressure ulcer prevalence and guideline adherence in pressure ulcer prevention. The five agencies were co-operating under one umbrella organization and were each located in one of the five Flemish provinces. Design and methods of the study were approved by the Interprovincial Board of Directors and by the Interprovincial Nursing Practice Committee. They agreed that the data collection did not interfere with the current nursing practice and therefore individual informed consent was not required (Buntinx \& De Lepeleire 2002).

\section{Population and sample}

A cluster randomized sample of nine regional nursing departments out of the existing 109 regional departments was chosen as a representative sample of the organization's patient population. Data were collected on all patients of the selected departments. Sample size calculation with Epi Info (Centers for Disease Control and Prevention 2001) indicated that a minimal sample size of 1700 was required for a population of 50000 to detect an expected prevalence of $10 \%$ with a precision of $2 \%$ and statistical power of $80 \%$, using $5 \%$ as the cut-off of statistical significance. The number of nine regional departments for the cluster sample was determined as follows. Four of the five agencies had between 20-30 regional departments; one agency had only 13 regional departments. Considering that patients of each province should have similar expected chances for inclusion, it was decided to draw a cluster sample of the patients by selecting at random two departments per agency, but only one regional department from the agency working through 13 regional departments. Random number tables (Hill 1984) were used for the selection of the nine departments.

\section{Data collection procedure}

Data were collected partly electronically and partly by paper forms. First, electronic data were extracted from the administrative databases: identification data, demographic data and data about the eligibility for nursing care and the reimbursement level. The patient's identification data were used to print an individual clinical report form for each subject, which was completed by the nurse who was responsible for the patient. The form was derived from European Pressure Ulcer Advisory Panel (EPUAP) registration forms used in previous studies (Clark et al. 2002). Face and content validity of the form was established by expert review and pilot testing. It included 26 standardized questions about risk factors, characteristics of pressure ulcers and preventive measures. The paper-based registration data were captured with the software package Teleform 7.0 (Cardiff Software 2000).

\section{Instruments}

A formal evaluation of the activities of daily living (ADL) was performed, using the Belgian Index of ADL (BIA) (Arnaert \& Delesie 1999), which is an adaptation of the Index of ADL (Katz et al. 1963). The adapted assessment tool evaluates the six original domains of the 'Index of ADL': bathing (personal hygiene), dressing, transfer, toileting, continence and eating 
(feeding). In contrast with the original scale, each function is scored 1-4, a higher score indicating higher dependency. A subject was considered as dependent for a function if the score was higher than 2. The global score can be deduced with the aid of a Boolean logic algorithm into one of four hierarchical dependency levels: baseline level (no or low-level dependency); level A (dependency for bathing, dressing and transfer or toileting); level B (dependency for bathing, dressing, transfer, toileting and continence or eating); level $\mathrm{C}$ the highest score for at least five functions, except continence or eating, which may have a score 3). The BIA is the official instrument used for reimbursement of nursing care by the federal Belgian health insurance. Home care clients reimbursed under at least level A dependency require daily hygienic care to be delivered. For subjects with lowlevel dependency, BIA-scores together with a doctor's attestation about the mental status, determine the subject's eligibility for daily hygienic nursing care. Interrater accuracy of the dependency evaluations is under continuous supervision of the medical and nurse advisors of health insurance agencies. One item questioned the subject's orientation status in three categories: 'no problem with orientation', 'sometimes a problem', 'always disoriented'. For the analysis of the orientation item, the categories 'sometimes a problem' and 'always disoriented' were merged, which resulted in a dichotomous score 'no problem' and 'having problems with orientation'.

In the present study, two criteria were used for the identification of persons at risk of developing pressure ulcers. First, a Dutch translation by Defloor et al. (2002) of the Braden Scale (Bergstrom et al. 1987) was used to estimate the subject's risk status. The Braden scale is comprised of six subscales: sensory perception, activity, mobility, moisture, friction/shear and nutrition. Each subscale is scored from $1-4$, with the exception of friction/shear, which is scored from 1-3. Summated scores range from 6-23. Lower scores indicate increasing risk for pressure ulcer development. A sum score $\leq 18$ was used as the cut-off to categorize the subjects as 'at risk' (Ferrell et al. 2000, Bergquist \& Frantz 2001, Bergquist 2005). Then, one item additionally questioned the clinical judgement of the nurse about the subject's risk status into two categories: 'at risk' or 'no risk'. According to Goodridge et al. (1998), the use of a risk assessment scale was not sufficient to determine pressure ulcer risk accurately. The clinical judgement and experience of nurses were required in providing supplementary information to standard measurement instruments. For the analysis of this study, a subject was considered as 'at risk' if 'at risk' according to at least one of the two criteria: the assessment using the Braden scale and/or the nurses' clinical judgement. In the present study, the kappa statistic for the agreement between the nurses' clinical judgement about pressure ulcer risk and the risk determination of the Braden scale cut-off was 0.71 (95\% confidence interval: $0 \cdot 68-0 \cdot 74)$. The observed agreement was $90 \%$ of all risk assessments.

Characteristics of the pressure ulcers were evaluated using the EPUAP-criteria for grading pressure ulcers: grade 1, nonblanchable erythema of intact skin; grade 2, blister, partial thickness skin loss involving epidermis, dermis, or both; grade 3, superficial ulcer, full thickness skin loss involving damage necrosis of subcutaneous tissue that may extend down to, but not through, the underlying fascia; grade 4, deep ulcer with extensive destruction, tissue necrosis, or damage to muscle, bone, or supporting structures with or without full thickness skin loss.

A checklist of the applied preventive measures was completed, including both materials used and interventions by home care nurses and informal carers. The BGPPU were used as reference standard to evaluate the effectiveness of the applied preventive measures. The checklist included questions about the participation of informal carers in pressure ulcer prevention. All participating nurses were trained by the investigators or the department's charge nurse in diagnosing pressure ulcers and scoring the Braden scale. They all received a copy of the instructions for scoring the Braden scale.

\section{Statistical analysis}

Categorical statistical tests and non-parametric methods for comparing categorical variables were used for data analysis. A $p$-value $<0.05$ was considered statistically significant. The SAS System (SAS Institute 2001) was used for statistical analysis. The combined age, sex and risk status distribution of the total study population was chosen as the reference distribution for calculating directly standardized prevalence rates adjusted for age, sex and risk status per regional department with Confidence Interval Analysis (Gardner et al. 1989). Age is known to have a high impact on the pressure ulcer occurrence (Bours et al. 2003, Tannen et al. 2004). In the present study, correction for age was performed because patients at risk and patients with pressure ulcers were older than patients not at risk ( $p=0.001$; Table 1$)$ and not having a pressure ulcer $(p=0.01$; Table 1$)$ ) respectively. Correction for sex was performed because there was a tendency for lower pressure ulcer risk prevalence $(p=0.08)$ and pressure ulcer prevalence $(p=0.05)$ in women (Table 1$)$.

Based on a subject's combination of preventive materials and measures, a SAS algorithm (Table 2) developed by the authors, was used to generate a summary evaluation score 
Table 1 Demographic and functional characteristics of study subjects. Statistical tests were performed to compare subjects at risk for developing pressure ulcers with subjects not at risk and to compare subjects having at least one pressure ulcer with subjects without pressure ulcers. Subjects at risk were partly the same as subjects with pressure ulcers

\begin{tabular}{|c|c|c|c|}
\hline & $\begin{array}{l}\text { Study } \\
\text { population } \\
n=2779\end{array}$ & $\begin{array}{l}\text { Subjects at risk for } \\
\text { developing pressure } \\
\text { ulcers } n=744\end{array}$ & $\begin{array}{l}\text { Subjects with } \\
\text { pressure ulcer } * * \\
n=188\end{array}$ \\
\hline Median age in years (IQR) & $78(70-84)$ & $80(71 \cdot 5-86)$ & $80(72 \cdot 5-85 \cdot 5)$ \\
\hline$p$-value & & $<0.001^{*}$ & $0 \cdot 01^{*}$ \\
\hline Women: $n(\%)$ & $1909(68 \cdot 7)$ & $492(66 \cdot 1)$ & $117(62 \cdot 2)$ \\
\hline$p$-value & & $0 \cdot 08 * *$ & $0 \cdot 05 *$ \\
\hline \multicolumn{4}{|l|}{ ADL dependency ${ }^{\dagger}: n(\%)^{\star}$} \\
\hline Baseline level & $1591(57 \cdot 3)$ & $159(21 \cdot 4)$ & $52(27 \cdot 7)$ \\
\hline Level A & $595(21 \cdot 4)$ & $170(22 \cdot 9)$ & $31(16 \cdot 5)$ \\
\hline Level B & $450(16 \cdot 2)$ & $281(37 \cdot 8)$ & $55(29 \cdot 3)$ \\
\hline Level C & $141(5 \cdot 1)$ & $133(17 \cdot 9)$ & $50(26 \cdot 6)$ \\
\hline$p$-value & & $<0.001 * *$ & $<0.001 * *$ \\
\hline Patients eligible for daily hygienic care: $n(\%)^{\ddagger}$ & $1758(63 \cdot 3)$ & $675(90 \cdot 7)$ & $166(88 \cdot 3)$ \\
\hline$p$-value & & $<0.001^{* *}$ & $<0.001 * *$ \\
\hline \multicolumn{4}{|l|}{ Orientation: $n(\%)^{*}$} \\
\hline No problem & $1990(71 \cdot 6)$ & $358(48 \cdot 2)$ & $97(51 \cdot 9)$ \\
\hline Sometimes a problem & $619(22 \cdot 3)$ & $275(37 \cdot 1)$ & $55(29 \cdot 4)$ \\
\hline Always disoriented & $168(6 \cdot 1)$ & $109(14 \cdot 7)$ & $35(18 \cdot 7)$ \\
\hline$p$-value & & $<0.001 * *$ & $<0.001 * *$ \\
\hline Median Braden scale sum score and IQR & $22(19-23)$ & $17(15-18)$ & $16(13-19)$ \\
\hline$p$-value & & $<0.001^{*}$ & $<0.001^{*}$ \\
\hline
\end{tabular}

IQR, interquartile range.

${ }^{\dagger}$ Dependency level according to the Belgian Index of ADL.

'Two values missing for the variables 'Belgian Index of ADL' and 'Orientation'.

*Wilcoxon test.

* Chi square test.

$* *$ Pressure ulcers were grade 1 (non-blanchable erythema) to grade 4 ulcers.

into one of three categories about the guideline adherence of the pressure ulcer prevention for that subject:

1 Adherence: All measures and materials present in the patient situation for the prevention of pressure ulcers were adherent to the BGPPU.

2 No adherence: Some or all measures and materials present in the patient situation for the prevention of pressure ulcers, were not adherent to the BGPPU or not recommended for pressure ulcer prevention by the BGPPU.

3 No prevention: There were no measures or materials for the prevention of pressure ulcers in the patient situation.

\section{Results}

Data were collected about 2779 patients between 3 March15 May 2003. Subjects ranged in age from 2-102 years, with a median age of 78 years. There were $2267(82 \%)$ patients above age 65 and 1116 (40\%) above age 80. Demographic and functional characteristics of the subjects are presented in Table 1.
According to the Braden scale or the clinical judgement of the nurses or both, $744(26.8 \%)$ subjects were at risk of developing pressure ulcers. A pressure ulcer was present in 188 cases resulting in a prevalence rate of $6.8 \%(95 \%$ $\mathrm{CI}=5 \cdot 9-7 \cdot 8 \%)($ Table 1$)$.

The prevalence was $7.3 \%$ in patients above age 65 and $8 \cdot 1 \%$ above age 80 . Prevalence for grade 2 pressure ulcers or higher was $4 \cdot 8 \%$ (133/2779). Standardized prevalence rates of individual regional departments ranged between $4 \cdot 9-9 \cdot 1 \%$ and did not differ significantly. Subjects at risk were partly the same as subjects with pressure ulcers. Of the 744 subjects at risk, 167 had pressure ulcers. The other 21 subjects with pressure ulcers were not considered as at risk based on the Braden scale assessment or the nurse's clinical judgement. Of the 133 subjects with grade 2 lesion or higher, 113 subjects were at risk and 20 subjects were not considered as at risk.

Risk status and the presence of a pressure ulcer were significantly associated to higher age, higher dependency levels, having difficulties with orientation and eligibility for daily hygienic care. The distribution of the Braden sum score 
Table 2 SAS algorithm: three steps for the determination of a summary score for guideline adherence in pressure ulcer prevention per patient situation
Steps of the algorithm

Step 1: Determination of the presence of measures or materials in adherence

Step 2: Determination of the presence of measures or materials not in adherence to the BGPPU*

Step 3: Determination of the absence of measures or materials for pressure ulcer prevention

Formats for the values of the variable 'adherence' to the BGPPU*

\section{SAS programming code}

If polyurethane_foam_mattress $=1$

or air_mattress $=1$ or alternating_mattress $=1$ or polyurethane_foam_pad $=1$ or air_cushion $=1$ or daily_skin_observation $=1$ or motivating_patient_carer $=1$ or lifting_heels $=1$ or position_change_day $>=1$ or position_change_night $=1$ then adherence $=1$;

If standard_foam_mattress $=1$ or water_mattress $=1$ or sheep_skin_bed $=1$ or standard_foam_pad $=1$ or water_pad $=1$ or gel_pad $=1$ or sheep_skin_armchair $=1$ or heel_protector $=1$ or film_dressing $=1$ or nutritional_supplements $=1$ or massage $=1$ or barrier_cream_lotion $=1$ then adherence $=2$;

If adherence $=$. then adherence $=3$;

$1=$ 'adherence'

$2=$ 'no adherence'

$3=$ 'no measures'
*BGPPU, Belgian Guideline for Pressure Ulcer Prevention

was significantly different between subjects with pressure ulcers (median sum score $=16$; IQR 13-19) and subjects without pressure ulcers (median sum score $=22$; IQR 20-23; Wilcoxon $p<0.001)$.

The total number of pressure ulcers was 228,78 pressure ulcers were grade 1 (34.2\%), 41 were grade $2(18.0 \%), 76$ were grade $3(33.3 \%)$ and 33 lesions were grade $4(14 \cdot 5 \%)$. There were 153 subjects with one pressure ulcer, 30 subjects presenting two pressure ulcers and five subjects presenting three pressure ulcers. The sacral region (107 subjects) and the heel (94 subjects) were the dominant locations for pressure ulcers. Most patients with a pressure ulcer at the hip (21 subjects) also had a pressure ulcer at the sacral region and/or the heel (13 subjects).

The applied preventive measures are presented in Table 3. The trends were similar in patients at risk and in subjects with pressure ulcers. Daily skin observation $(48.4 \%$ of the subjects at risk) and position changes during the day $(42.3 \%$ of the subjects at risk), were the most frequently applied measures in adherence to the BGPPU. The frequency of use of a barrier cream or lotion for pressure ulcer prevention $(52.8 \%$ of the subjects at risk) was the most frequent of the measures which were not compliant with the BGPPU. The use of adequate materials was low: an alternating mattress was the most frequently used BGPPU-compliant device in persons with pressure ulcers $(12 \cdot 2 \%)$.

Overall, of the 744 subjects at risk of developing pressure ulcers, $33(4.4 \%)$ received preventive measures which were in adherence to the BGPPU, 482 persons $(64.8 \%)$ were administered measures which were not in adherence to the BGPPU and in 229 subjects $(30.8 \%)$ at risk for developing pressure ulcers prevention was lacking. The administration of preventive measures was significantly associated to characteristics of the subjects at risk. Subjects at risk with prevention were older, had higher ADL dependency, worse skin condition and more pressure ulcers than at risk subjects without prevention (Table 4). For subjects with at least one pressure ulcer, adherence to the BGPPU was: $4.8 \%$ adherence, $76 \cdot 6 \%$ no adherence and $18.6 \%$ no prevention.

Approximately one quarter of the patients and informal carers $(22.2 \%$ of the patients at risk and $26.6 \%$ of the patients with a pressure ulcer) were informed and motivated by the visiting nurse about participation in pressure ulcer prevention (Table 3). Informal carers actively participated in changing the position of $159(21.4 \%)$ of the subjects at risk and of $52(27 \cdot 7 \%)$ of the subjects with pressure ulcers.

\section{Discussion}

In the present study about Flemish home nursing patients, the pressure ulcer prevalence was low. Low pressure ulcer prevalence may have been due to underreporting. Several authors reported frequent underreporting of pressure ulcer prevalence and incidence (Allcock 1994; Benbow 2004). There may have been four causes for underreporting. First, underreporting of newly developed pressure ulcers was considered a potential problem in the home healthcare setting, because nurses may not perform skin assessment over pelvic bony prominences at each visit and patients may forget to report a suspect or former lesion during the home health visit (Bergquist \& Frantz 2001). Second, because in the present study the data were not collected by neutral research assistants but by the nurses who were performing the daily nursing care, low pressure ulcer prevalence may 
Table 3 Application of measures and materials for the prevention of pressure ulcers in 744 patients at risk for developing pressure ulcers and in 188 patients with at least one pressure ulcer. Subjects at risk were partly the same as subjects with pressure ulcers

\begin{tabular}{|c|c|c|c|}
\hline Preventive measures and materials & $\begin{array}{l}\text { Recommen-dation } \\
\text { for use in pressure } \\
\text { ulcer prevention } \\
\text { by the BGPPU? }\end{array}$ & $\begin{array}{l}\text { Application in } \\
744 \text { patients at } \\
\text { risk for developing } \\
\text { pressure ulcers, } n(\%)\end{array}$ & $\begin{array}{l}\text { Application in } \\
188 \text { patients with } \\
\text { pressure ulcer*, } \\
n(\%)\end{array}$ \\
\hline \multicolumn{4}{|l|}{ In bed } \\
\hline Polyurethane foam mattress & $\mathrm{R}$ & $38(5 \cdot 1)$ & $8(4 \cdot 3)$ \\
\hline Air mattress & $\mathrm{R}$ & $36(4 \cdot 8)$ & $18(9 \cdot 6)$ \\
\hline Alternating mattress & $\mathrm{R}$ & $54(7 \cdot 3)$ & $23(12 \cdot 2)$ \\
\hline Mousse mattress & NR & $143(19 \cdot 2)$ & $35(18 \cdot 6)$ \\
\hline Water mattress & NR & $26(3 \cdot 5)$ & $11(5 \cdot 9)$ \\
\hline Sheep skin & NR & $89(12 \cdot 0)$ & $30(16 \cdot 0)$ \\
\hline \multicolumn{4}{|l|}{ In armchair } \\
\hline Polyurethane foam pad & $\mathrm{R}$ & $28(3 \cdot 8)$ & $10(5 \cdot 3)$ \\
\hline Air cushion & $\mathrm{R}$ & $42(5 \cdot 6)$ & $15(8 \cdot 0)$ \\
\hline Mousse pad & NR & $53(7 \cdot 1)$ & $8(4 \cdot 3)$ \\
\hline Water pad & NR & $31(4 \cdot 2)$ & $12(6 \cdot 4)$ \\
\hline Gel pad & NR & $54(7 \cdot 3)$ & $17(9 \cdot 0)$ \\
\hline Sheep skin & NR & $66(8 \cdot 9)$ & $25(13 \cdot 3)$ \\
\hline \multicolumn{4}{|l|}{ Other } \\
\hline Daily skin observation & $\mathrm{R}$ & $360(48 \cdot 4)$ & $109(58 \cdot 0)$ \\
\hline Motivating patient and informal carers & $\mathrm{R}$ & $165(22 \cdot 2)$ & $50(26 \cdot 6)$ \\
\hline Lifting heels & $\mathrm{R}$ & $78(10 \cdot 5)$ & $39(20 \cdot 7)$ \\
\hline Position change during the day & $\mathrm{R}$ & $315(42 \cdot 3)$ & $100(53 \cdot 2)$ \\
\hline Position change at night & $\mathrm{R}$ & $75(10 \cdot 1)$ & $22(11 \cdot 7)$ \\
\hline Heel muff & NR & $69(9 \cdot 3)$ & $31(16 \cdot 5)$ \\
\hline Film dressing & NR & $47(6 \cdot 3)$ & $24(12 \cdot 8)$ \\
\hline Nutritional supplements & NR & $24(3 \cdot 2)$ & $14(7 \cdot 4)$ \\
\hline Massage & NR & $108(14 \cdot 5)$ & $34(18 \cdot 1)$ \\
\hline Barrier cream or lotion & NR & $393(52 \cdot 8)$ & $120(63 \cdot 8)$ \\
\hline
\end{tabular}

BGPPU, Belgian Guideline for the Prevention of Pressure Ulcers; R, recommendable for use in pressure ulcer prevention according to BGPPU; $\mathrm{NR}$, not recommendable for use in pressure ulcer prevention according to BGPPU.

*Pressure ulcers were grade 1 (non-blanchable erythema) to grade four ulcers.

also result from socially desirable answers given by the nurses. The presence of pressure ulcers is often considered as an indicator of low quality of care and nurses may have been negatively influenced in correctly reporting the presence of pressure ulcers. Inaccurate pressure ulcer risk assessment may have been a third source of under-registration of pressure ulcers. Benbow (2004) reported this phenomenon by stating that $57 \%$ of the patients with pressure ulcers were not reported as at risk. In the present study, there were indications of inaccurate risk assessment: an important proportion of subjects with pressure ulcers $(21 / 188=11 \cdot 2 \%)$ was not considered as at risk based on the Braden scale assessment or the nurse's clinical judgement. Fourth, it may have been difficult for nurses to distinguish grade 1 ulcer (non-blanchable erythema) from blanchable erythema (Allcock et al. 1994) and consequently $6.8 \%$ might be an underestimation of pressure ulcer prevalence.
These findings demonstrate that the nurses' clinical competence with regard to pressure ulcer risk assessment and pressure ulcer grading needs to be improved through education and training. Nurses should be attentive to assess and recognise pressure ulcer risk and to label patients effectively as at risk when the risk status is determined.

One year after the publication of the BGPPU, the adherence of nurses and clients to the BGPPU was low: only a very small proportion of patients at risk were administered preventive measures which were adherent to the BGPPU. In most cases at risk the pressure ulcer prevention consisted of measures, which were not recommended by the BGPPU. Pressure ulcer prevention was lacking in an important proportion of patients at risk. Other investigators have described inappropriate pressure ulcer prevention in home health care (Ferrell et al. 2000, Bergquist 2005). In the present study, the main reason for suboptimal quality of pressure ulcer prevention may have been that pressure ulcer 
Table 4 Presence and absence of pressure ulcer prevention in subjects at risk for developing pressure ulcers. Statistical tests were used to test for differences between subjects with and without prevention

\begin{tabular}{|c|c|c|c|}
\hline Characteristics & $\begin{array}{l}\text { Subjects } \\
\text { with } \\
\text { prevention } \\
(n=515)\end{array}$ & $\begin{array}{l}\text { Subjects } \\
\text { without } \\
\text { prevention } \\
(n=229)\end{array}$ & $p$-value \\
\hline Median age in years (IQR) & $80(72-82)$ & $78(69-85)$ & $0 \cdot 04 *$ \\
\hline Women: $n(\%)$ & $346(67 \cdot 2)$ & $146(63 \cdot 8)$ & $0 \cdot 36^{* *}$ \\
\hline $\begin{array}{l}\text { Median Braden scale sum } \\
\text { score (IQR) }\end{array}$ & $16(14-18)$ & $18(17-18)$ & $<0 \cdot 001^{*}$ \\
\hline \multicolumn{4}{|l|}{ ADL dependency: $n(\%)$} \\
\hline Baseline & $74(14 \cdot 4)$ & $85(37 \cdot 3)$ & $<0.001 * *$ \\
\hline Level A & $102(19 \cdot 8)$ & $68(29 \cdot 8)$ & \\
\hline Level B & $219(42 \cdot 5)$ & $62(27 \cdot 2)$ & \\
\hline Level C & $120(23 \cdot 3)$ & $13(5 \cdot 7)$ & \\
\hline \multicolumn{4}{|l|}{ Skin condition: $n(\%)$} \\
\hline Normal skin & $186(36 \cdot 1)$ & $164(71 \cdot 6)$ & $<0.001 * *$ \\
\hline Blanchable erythema & $184(35 \cdot 7)$ & $43(18 \cdot 8)$ & \\
\hline Non-blanchable erythema & $47(9 \cdot 1)$ & $7(3 \cdot 1)$ & \\
\hline Blister & $26(5 \cdot 1)$ & $5(2 \cdot 2)$ & \\
\hline Superficial ulcer & $50(9 \cdot 7)$ & $6(2 \cdot 6)$ & \\
\hline Deep lesion & $22(4 \cdot 3)$ & $4(1 \cdot 8)$ & \\
\hline \multicolumn{4}{|c|}{ Number of pressure ulcers including non-blanchable erythema: $n(\%)$} \\
\hline No ulcer & $370(71 \cdot 9)$ & $207(90 \cdot 4)$ & $<0.001 *$ \\
\hline One ulcer & $114(22 \cdot 1)$ & $18(7 \cdot 9)$ & \\
\hline Two ulcers & $27(5 \cdot 2)$ & $3(1 \cdot 3)$ & \\
\hline Three ulcers & $4(0 \cdot 8)$ & $1(0 \cdot 4)$ & \\
\hline \multicolumn{4}{|c|}{$\begin{array}{l}\text { Number of pressure ulcers grade } 2 \text { or higher (excluding } \\
\text { non-blanchable erythema): } n(\%)\end{array}$} \\
\hline No ulcer & $417(81 \cdot 0)$ & $214(93 \cdot 5)$ & $<0.001 *$ \\
\hline One ulcer & $82(15 \cdot 9)$ & $14(6 \cdot 1)$ & \\
\hline Two ulcers & $16(3 \cdot 1)$ & $1(0 \cdot 4)$ & \\
\hline
\end{tabular}

IQR, interquartile range.

*Calculated using the Wilcoxon test.

* Calculated using the chi squared test.

prevention was not sufficiently integrated into the existing care delivery system. Implementation must go beyond merely creating guidelines and educating nursing staff (Xakellis et al. 2001).

A merit of the study was that the attention was drawn to the role of the patient and the informal carers. While the importance of their contribution to the pressure ulcer prevention is commonly accepted, only a limited proportion of the patients at risk and their informal carers was informed and motivated by the nurse to participate actively in the pressure ulcer prevention and their actual participation in the prevention was low. As reported previously (Ferrell et al. 2000), the patients and their informal carers may not have had the required knowledge to provide optimal prevention. These findings confirm earlier publications about the constraints experienced by district nurses and the low priority that is given to patient education by nurses (Ayello et al. 1997, Cantrell 1998).

\section{Study limitations}

A major limitation of the generalisability of the findings of this study was the fact that it was conducted in a limited number of regional departments of collaborating home nursing agencies, which were not representative for home nursing in Flanders or in Belgium. The results should therefore be interpreted cautiously.

A second limitation was the fact that the assessment of the pressure ulcers and the risk status was not performed by trained nurses but by all the home care nurses of the nine selected regional departments. The nurses received only limited education and training from the authors about the EPUAP-criteria for grading pressure ulcers and the risk assessment. Additionally, using only one source of information is another weakness of the study design. It would have been better to rely on multiple sources for assessing guideline compliance in a patient situation and cross-compare the data (Saliba et al. 2003).

The study gives insight in the pressure ulcer prevention practices in home health care. It does not completely describe all aspects of the prevention. Several simplifications were made in the assessment of guideline adherence. For example, position change would only be adherent to the BGPPU when it was performed every 2-4 hours for 24 hours a day and seven days a week. In this study, the definition of guideline adherence for position change was set at a minimal level: when position change was performed at irregular intervals during the day or night. Minimal level definition of guideline adherence was also used by Saliba et al. (2003) to allow for the possibility that documentation may not detail all care processes that were performed. As a consequence, the evaluation of the guideline adherence was not sufficient for a final judgement about the client's quality of pressure ulcer care. Therefore, additional information would have been required. For example, it would have been necessary to perform assessments about the completeness and the continuity of the preventive measures. These important aspects of the pressure ulcer prevention were not investigated in our study. The quality of pressure ulcer prevention processes is a complex and a multi-faceted concept. This complexity may explain why it is difficult to link process to outcome of pressure ulcer care, as was stated by Thomas and Osterweil (2005). It seems important that quality indicators, which are used to explain differences in pressure ulcer incidence between nursing departments maximally take account of the different aspects of the nursing process in pressure ulcer prevention. 


\section{Conclusions}

Adherence of nurses and patients to the BGPPU was low. Nurses and home care clients were not familiar with the BGPPU. It is highly recommendable that home healthcare organizations develop and implement educational strategies with regard to pressure ulcer prevention which address professionals, patients and informal carers.

\section{Conflict of interest}

Louis Paquay, Renild Wouters, Roseline Debaillie and Ludo Geys are employees of 'Wit-Gele Kruis van Vlaanderen'.

\section{Author contributions}

Study design: LP, TD, FB, RD, LG; Data collection and analysis: LP, RW; Manuscript preparation: LP, RW, TD, FB, RD.

\section{References}

Allcock N, Wharrad H \& Nicolson A (1994) Interpretation of pressure sore prevalence. Journal of Advanced Nursing 20, 37-45.

Arnaert A \& Delesie L (1999) Calibration of measurement data: the Belgian Institute of Health Insurance Index of ADL. [IJking van meetgegevens: RIZIV A.D.L.-index]. Acta Hospitalia 39, 19-31.

Ayello EA, Mezey M \& Amella EJ (1997) Educational assessment and teaching of older clients with pressure ulcers. Clinics in Geriatric Medicine 13, 483-496.

Baier RR, Giggord DR, Lyder CJ, Schall MW, Funston-Dillon DL, Lewis JM \& Ordin DL (2003) Quality improvement for pressure ulcer care in the nursing home setting: the Northeast Pressure Ulcer Project. Journal of the American Medical Directors Association 4, 291-301.

Bates-Jensen BM, Cadogan M, Osterweil D, Levy-Storms L, Jorge J, Al-Samarrai N, Grbic V \& Schnelle JF (2003) The minimum data set pressure ulcer indicator: does it reflect differences in care processes related to pressure ulcer prevention and treatment in nursing homes? Journal of the American Geriatrics Society 51, 1203-1212.

Benbow M (2004) Pressure ulcer incidence reporting. Nursing Standard 18, 57-60, 62, 64 passim.

Bergquist S (2005) The quality of pressure ulcer prediction and prevention in home health care. Applied Nursing Research 18, 148-154.

Bergquist S \& Frantz R (1999) Pressure ulcers in community-based older adults receiving home health care. Prevalence, incidence and associated risk factors. Advances in Wound Care 12, 339351.

Bergquist S \& Frantz R (2001) Braden scale: validity in communitybased older adults receiving home health care. Applied Nursing Research 14, 36-43.

Bergstrom N, Braden BJ, Laguzza A \& Holman V (1987) The Braden scale for predicting pressure sore risk. Nursing Research 36, 205-210.
Bours GJ, Halfens RJ, Berger MP, Huijer Abu-Saad H \& Grol RT (2003) Development of a model for case-mix adjustment of pressure ulcer prevalence rates. Medical Care 41, 45-55.

Buntinx F \& De Lepeleire J (2002) Ethical aspects of epidemiological research in the elderly: a consensus. [Ethische aspecten van epidemiologisch onderzoek bij bejaarden: consensustekst]. Tijdschrift voor Geneeskunde 58, 1642-1647.

Cantrell J (1998) District nurses' perceptions of health education. Journal of Clinical Nursing 7, 89-96.

Cardiff Software (2000) Teleform Version 7.0. Computer Program. Cardiff Software, Inc., Vista, CA.

Centers for Disease Control and Prevention (2001) Epi Info Version 6.04d. Computer Program. World Health Organization, Geneva.

Chaves LM, Grypdonck MHF \& Defloor T (2006) Pressure ulcer prevention in homecare. do dutch homecare agencies have an evidence-based pressure ulcer protocol? Journal of Wound, Ostomy and Continence Nursing 33, 273-280.

Clark M, Bours G \& Defloor T (2002) Summary report on the prevalence of pressure ulcers. EPUAP Review 4, 49-57.

Defloor T, Van den Bossche K, Derre B, Feyaerts S \& Grypdonck M (2002) Belgian Guideline for Prevention of Pressure Ulcers. [Belgische richtlijnen voor decubituspreventie]. Academia Press, Gent. Available at: http://www.decubitus.be (accessed 19 July 2007).

Ferrell BA, Josephson K, Norvid P \& Alcorn H (2000) Pressure ulcers among patients admitted to home care. Journal of the American Geriatrics Society 48, 1042-1047.

Gardner SB, Winter PD \& Gardner MJ (1989) Confidence Interval Analysis Version 1.0. Computer Program. British Medical Association, London.

Goodridge DM, Sloan JA, LeDoyen YM, McKenzie JA, Knight WE \& Gayari M (1998) Risk-assessment scores, prevention strategies and the incidence of pressure ulcers among the elderly in four Canadian health-care facilities. Canadian Journal of Nursing Research 30, 23-44.

Gould D, Darpey A \& Fox C (2000) Consumer views of pressure sores: a preliminary survey. Nursing Standard 14, 49-52.

Halfens RJG \& Bours GJJW (2002) The measurement of the outcome of care: decubitus. [Het meten van een zorgresultaat: decubitus]. TvZ Tijdschrift voor Verpleegkundigen 112, 42-45.

Halfens RJG, Bours GJJW \& Bronner CM (2001) The impact of assessing the prevalence of pressure ulcers on the willingness of health care institutions to plan and implement activities to reduce the prevalence. Journal of Advanced Nursing 36, 617-625.

Hill AB (1984) A Short Textbook of Medical Statistics. Hodder and Stoughton, London.

Katz S, Ford A, Moskowitz R, Jackson B \& Jaffe M (1963) Studies of illness in the aged. Journal of the American Medical Association 185, 914-919.

Kwaliteitsinstituut voor de Gezondheidszorg CBO (2002) Decubitus. Tweede herziening. Available at: http://www.cbo.nl/product/richtlijnen/folder20021023121843/decubitus2002.pdf (accessed 19 July 2007).

Maklebust J (1999) Preventing pressure ulcers in home care patients. Home Healthcare Nurse 17, 229-237.

Meehan M, O'Hara L \& Morrison YM (1999) Report on the prevalence of skin ulcers in a home health agency population. Advances in Wound Care 12, 459-467. 
Panel for the prediction and Prevention of Pressure Ulcers in Adults (AHCPR) (1992) Pressure ulcers in adults: Prediction an prevention. Clinical Practice Guideline Number 3. AHCPR Publication No. 92-0047. Rockville, MD: Agency for Health Care Policy and Research, Public Health Service, U.S. Department of Health and Human Services. Available at: http://www.ncbi.nlm.nih.gov/ books/bv.fcgi?rid=hstat2.chapter.4409 (accessed 16 January 2007).

Saliba D, Rubenstein LV, Simon B, Hickey E, Ferrell B, Czarnowski E \& Berlowitz D (2003) Adherence to pressure ulcer prevention guidelines: implications for nursing home quality. Journal of the American Geriatrics Society 51, 56-62.

SAS Institute (2001) The SAS System Release 8.02. Computer Program. SAS Institute, Cary, NC.

Shekelle PG, Ortiz E, Rhodez S, Morton SC, Eccles MP, Grimshaw JM \& Woolf SH (2001) Validity of the agency for healthcare research and quality clinical practice guidelines. Journal of the American Medical Association 286, 1461-1467.

Tannen A, Dassen T, Bours G \& Halfens R (2004) A comparison of pressure ulcer prevalence: concerted data collection in the Netherlands and Germany. International Journal of Nursing Studies 41, 607-612.

Thomas DR \& Osterweil D (2005) Is a pressure ulcer a marker for quality of care? Journal of the American Medical Directors Association 6, 228-230.

Wipke-Tevis DD, Williams DA, Rantz MJ, Popejoy LL, Madsen RW, Petroski GF \& Vogelsmeier AA (2004) Nursing home quality and pressure ulcer prevention and management practices. Journal of the American Geriatrics Society 52, 583-588.

Xakellis GC, Frantz RA, Lewis A \& Harvey P (2001) Translating pressure ulcer guidelines into practice: it's harder than it sounds. Advances in Skin \& Wound Care 14, 249-256, 